\title{
Background Factors and Female Dominance
}

\author{
Asghar Mirardi \\ Faculty of Sociology, Yasooj University, Iran
}

\author{
Ali Edalati (Corresponding author) \& Ma'rof Redzuan \\ Faculty of Human Ecology, University Putra Malaysia \\ 43400 Serdang, Selangor, Malaysia \\ Tel: 60-1-2279-3206Ｅ-mail: alisq2008@yahoo.com
}

\begin{abstract}
The aim of this study is examine the relationship between duration of marriage, number of children, years of education and family income with female dominance. The study employed survey design. It was carried out among a sample of 337 married women in Shiraz City, Iran. Hamby Dominance Scale (HDS) was used to measure romantic dominance. The study employed correlations test to determine the relationships between duration of marriage, number of children, years of education and family income with female dominance. The study found that there were not significant relationships between duration of marriage, women education and women age with female dominance. There were significant relationship between number of children and family income with female dominance. The result of Regression Analysis showed that the number of children and family income factors contributed $7.4 \%$ in explaining the female dominace.
\end{abstract}

Keywords: Dominance, Female dominance, Women dominance, Women

\section{Introduction}

The meaning of dominance in society is not clear. Theoreticians have different ideas about conceptualizing aspects of dominance in families however many scholars use the term "decision making" for dominance in families. When it is questioned who holds authority, it specifically refers to decision making in the families. Moreover, the criterion of authority among couples can determine the degree of patriarchy in families (Saroukani, 2005).

Hamby (1996) defines dominance as any attempts that a life partner makes to take control over the other partner. He mentioned three different forms of dominance, i.e, authority, restrictiveness, and disparagement. Sarookhani (2005) has defined dominance in terms of the decision maker within family. The person who makes the final decision is the dominant person. Dominance is generally and traditionally related with male aggression (Sarookani 2005; Lajvardi 2004). Traditional dominance belongs previously to the men but nowadays male dominance is no longer accepted because of changes in rules and equality in the society especially the increasing level of knowledge and education wherein women are looking for equality. Dominance has been discussed frequently because there is a challenge to keep it. That is why analysts are presently trying to recognize the authority in the families, that is, who should hold the authority and make decisions. Dominance and the phenomenon of acquiring it serve a historical event and are practically and mentally considered.

Another study found that with an increase level of education and knowledge will decrease the level of dominance. In a measurement research in the context of the current study, from a sample of 300 married women of Shiraz, Mansourian \& Ghaderi (2002) have investigated in regard to power dominance in the families. Based on the results, husband and wife's education is one of the significant variables in relation to power dominance in families. The women who have higher educational levels have a more crucial role in cooperation and resolution. There existed a negative significant relationship between man's education and his exerting power in families. In other words, the more educated the men are, the less power dominance there will be and women have more chances in cooperating with the relationship. These findings show that more modern families have more equal power in their relation.

With regard to the prevalence of dominance, Mahdavi, \& Saburi (2003) investigated dominance distribution in families living in Tehran. They studied a 200 married woman sample that had at least one child. According to the outcomes, the structure of $37.5 \%$ of Tehran families is democratic; $39 \%$ of them are democratic only to some extent, and $23.5 \%$ of families have structures other than democratic. Factors such as conception of husband's tendency toward exercising power against his wife, women's conception about their obedient roles, women's 
collaboration in choosing their husbands and women's level of education have had crucial roles in the quality and quantity of democratic structure of families. These findings show that dominance is a usual phenomena in the Iranian context and prevalent mostly in the families.

Molaverdi (1999), in an article named " Causes and roots of family violence " nominates the causes of violence as follows: inequalities between men and women in terms of power and dominance, enjoyment (regarding job and economical relations, family and scientific as well as educational relations), nature of cultural patterns resulting from false customs and fanatical opinions; the idea of doing things in secret; problem solving methods in the family entanglements; government faults, the effect of childhood events, the impact of mass media, using drugs, medicine, alcohol as well as situational factors and personality characteristics.

The prevalence of dominance in the families, Lajvardi (1997) in her research in Tehran city found that all respondents mentioned that the structure of their family was not patriarchal, and in most of the families they decided mutually $(60 \%)$. Saroukhani \& Amirpanahi (2006) studied the effect of power in family on social participation among the adults. They found that in those families which were democratic and egalitarian, their social participation was high and also were less aggressive in their relations with the other members of the family. The study was carried out in Tehran in 2004 and 391 people living in Tehran were included in their study.

\section{Methodology}

The main objective of this study was to determine the relationships between duration of marriage, number of children, years of education and family income with female marital satisfaction. To achieve this objective, the study was carried out among married women in Shiraz City, Iran. Shiraz City, the central part of the Fars Province which has approximately the population of around 1,800,000 people. Shiraz City provided the researcher with a valid sample of women for the study. Thus, some cities of Fars Province, such as Larestan, Jahrom, Fasa, Lamerd, Marvdasht, Estahban, Mohr, Abadeh and Kazeroon were not included in this study due to the high financial cost.

The study employed survey design, where 346 married women involved in the study. The number of respondents invloved (sample size) was determined using a formula suggested by Krejcie \& Morgan (1970). The population of the study includes all married women above 18 years of age. This study does not include single or divorced women since these people either had not started their married family or did not have a complete family. The total population of this study has included 3510 women from different clinics in Shiraz city. Women from various social groups and parts of Shiraz City were the population of this study, who were culturally, religiously and ethnically heterogeneous. In order to obtain greater representation of the given population and decrease the probable sampling error, the study has utilized a stratified random sampling.

The Shiraz City was divided into six regions, and from each region a number of clinics was chosen randomly. From each clinic, the sample was chosen according the proportional number of women that were referred to. The selection of the respondents used simple random sampling technique, where the respondets were chosen randomly from the sampling frame (the list of names of the potential respondents in the particular clinic). From the clinics in region one. $53(15.31 \%)$ respondents were selected, region two $55(15.89 \%)$ respondents, region three $55(15.89 \%)$ respondents, region four $58(16.76 \%)$ respondents, region five 60 (17.34) respondents, and region six $65(18.78 \%)$ respondents. After choosing the sample and obtaining written consent, the questionnaires were distributed among the sample in person and with the help of other colleagues who were experienced in conducting survey research. However, for those women who have been chosen as respondents, but refused to participate, they were replaced by other women in the same list in which they were selected randomly.

Hamby (1995) developed a 32 Likert-type item scale that examines three forms of dominance such as authority, restrictiveness and disparagement which is called Hamby Dominance Scale (HDS). The term "Authority "refers to the power of decision making in a relationship. Restrictiveness describes when a partner feels he has the right to intrude upon the behavior of the other one, even when that behavior does not directly involve them, indicating: "I respect my partner's need for privacy" (Hamby, 1996). Furthermore, Hamby describes disparagement ("My partner is basically a good person.") as the failure of one partner to evaluate the other partner equally in addition to the overall negative view about the worth of their partnership.

The items were rated from 1 (strongly agree) to 4 (strongly disagree). Data from this scale supports the internal validity of each of these three constructs. The dominance questionnaire reliability coefficient was observed as 0.85 . The translation of this instrument, whose validity and reliability had already been established, was given to the participants. Respondents were asked about the degree of their agreements (on a 4-point scale) about each item.

For data analysis, this study employed a correlation coefficient statistical analysis that investigates how scores on one variable or variables decrease or increase as there is a change in the scores of the other variable(s). 
Product-moment correlation were calculated to determine the degree of relationship. Positive correlation coefficient index (r) indicated a positive relationship, while a negative coefficient reflected otherwise. The Multivariate Regression Analysis was used to answer the last objective.

\section{Results}

The descriptive data of the participants is provided in two tables (Table 1, Table 2 and Table 3). The backgrounds of the respondents are illustrated in Table 1.

\section{Insert Table 1 Here}

There are five background variables investigated in this paper, namely, age, duration of marriage, education, number of childre and family's total income. Table 1 reveals the frequency distribution of the variables. The Table1 shows women's age from 18 to 58, with more than half of the women $199(59.05 \%)$ who were 30 years old and below. However, only a few respondents, i.e. 7 (2.08\%) were 50 years and above. As such, most of the respondents $317(87.83 \%)$ were below 40 years old. From the tabulated data and with respect to the observed values, it could be claimed that the age range of the married wives is appropriate according to the social norms of the context of this research. Moreover, the population is assumed to approaching normality where the values observed are $\mathrm{M}=30.77$ and $\mathrm{SD}=7.96$. The average age of 30 years for the respondent will contribute to the appropriateness of the sampled population as well as the representativeness of the sample.

Moreover, educational background, as and indicator of academic achievement of the respondents, was also investigated. Based on the educational system of the context of this research, the first category was intended for primary school (1-5 years study), second category was secondary school (6-9 years), the third category was high school (10-13 years) and the final category was 14 years and above for university education. This classification is assumed to include all the participating wives in the research. Table 1 shows that most of the respondents have a high school degree $123(36.72 \%)$ and $116(34.62 \%)$ of them have a primary school degree. Approximately, 57 $(17.01 \%)$ have secondary school degrees. The lowest percentage of women education was $39(11.64 \%)$ belonging to university level. From the tabulated data, it could be inferred that, the sample is normally distributed around the three levels of education in accordance with the current educational system in Iran, i.e., one-third have primary education, one-third have completed high school and have married, and the rest either have quitted education before high school or have continued for the higher education to the universities. As observed in Table 1, most of the respondents have diploma education or above. High school education level and university level may indicate that it has played an effective role in enhancing and improving the level of women's knowledge and awareness due to education. Women have started to leave the traditional boundaries and are joining the social community. The high number of women at universities is evidence for the claim that they are more getting involved in social participations.

Another variable which has been investigated is the duration of marriage. The observed mean for duration of marriage is 9.62 years $(\mathrm{SD}=9.1)$. This could be interpreted as these couples have been living together for almost 10 years. However, $156(46.29 \%)$ of families have been living together for less than five years. Moreover, it was observed that $83(24.63 \%)$ have lived together for $5-10$ years. Around $24(7.12 \%)$ of respondents have been living with each other for 11-15 years, and 24 (7.12\%) of them have lived with each other for 16-20 years. Finally it was observed that $50(14.84 \%)$ have been living with each other for more than 20 years.

The number of children constitutes the other variable in the current research. From the collected demographic questionnaire, it was found out that $270(80.12 \%)$ of the respondents had only one child or none. Another 63 $(18.69 \%)$ of the sample had 2-4 children. For the relatively large families it was observed that, $3(0.89 \%)$ between had 5-7 children and $1(0.29 \%)$ had more than seven children consecutively. More than $80 \%$ of the respondents had either no children or only one child. In the past, most families had many children and women were usually involved in the majority of housekeeping duties and childcare. Nowadays, with an increase in the level of education, children are viewed differently. Having children, especially male children, is no longer a general basis for Iranian families. Many families are satisfied with having two children, regardless of the gender. The improvement in education level as well as propaganda from the government has caused families to pay more attention to the quality of childcare rather than the quantity and gender. Contrary to the past, many families are nuclear rather than extended.

Another variable was the "total of family income". The observed mean for the family income is 4504360 (in Iranian currency, Rials) and its standard deviation was observed 352681.83, which is relatively far from the observed mean of 450436 . Therefore, it can be inferred that the sample of the current research are abnormally scattered as far as their level of total family income is concerned. 
There were $51(15.36 \%)$ of respondents who had an income less than 2000,000 Rials. The majority of family's income is in the category of 2000,000-4000,000, $151(45.48 \%)$, and $78(23.49 \%)$ of them have a monthly income of 4000,001-6000,0000 Rials. The other members of the sample which is about $52(15.66 \%)$ have an income of more than 6000,0000 Rials. A review of the Labour Regulations in 2008 shows that this is within the normal ranges as in Iran the minimum wage is 3,000,0000 Rials for workers and employees (Ministry of Labour and Social Affairs, 2008). As such, all family incomes fall under the middle area of normal curve. However, these families are not socially classified as rich based on their level of income.

The category of income shows that most of the families had either an average or low income. Approximately $85 \%$ of them have a monthly income rate lower than 6,000,000 Rials. This is an average income rate for Iranian families. The high income class and low income class comprise $15 \%$ of the whole society each so considering the whole population, the sample of this study is normal. According to the Ministry of Labour and Social Affairs (2008), the employers must pay a minimum monthly income of 3,000,000 Rials and the participants of the study do not violate this fact.

Table 1 depicts the findings related to the backgrounds of the respondents. The Pearson's Product-Moment Correlation Test was used to test the relationships between background of the respondents and their dominance. Table 2 shows the results of the analysis.

\section{Insert Table 2 Here}

The results could be summarized as follows:

i. There is no significant relationship between respondents' duration of marriage and dominance, where $r=$ $-.037, p>.05$.

ii. There is no significant relationship between respondents' age and dominance, where $r=.100, p>.05$.

iii. There is a positive significant relationship between respondents' number of children and dominance, where $r=.151, p<.05$.

iv. There is a ppositive significant relationship between respondents' family income and dominance, where $r=.245, p<.05$.

v. There is no significant relationship between respondents' years of education and dominance, where $r=-.103$, $p>.05$.

\section{Insert Table 3 Here}

The Multivariate Regression Analysis was used to determine factors that contribute in explaining psychological aggression. The result shows that two predictor variables, namely number of children and family income were found to be significant in explaining the observed variation in dominance. However, the three predictors has explained $7.4 \%$ of total observed variance to female dominace $\left(\mathrm{R}^{2}=.704\right)$.

\section{Conclusion and Discussion}

The rationale of the current article is to examine the relationship between duration of marriage, number of children, years of education and family income with female dominance. The results showed that there were not significant relationships between duration of marriage, women education and women age with female dominance. There were significant relationship between number of children and family income with female dominance.

At present, women are rejecting male dominance and inequality and demand for equal power in the family. When women become more educated, they will develop this kind of perception. The experience they learned from school, university, mass media and their interactions with society influenced them to believe that women have equal right as man and are not lower than men which are in line with concepts of social learning theory.

\section{Limitation of the Study}

Major constraint regarding local literatures also serves as a limitation to the current as this is one of the few attempts research carried out on the topic in Iran. In addition, limiting the study to the respondents' perception and understanding concepts of dominance may have affected the result of the study. A further limitation of the study lies in its concentration on women. The study was not able to focus on men because they were not accessible and only women were referred to clinic for consultation and counselling.

\section{Recommendation for future Research}

This study has focused on clinical samples, so the future researchers can replicated this present study by using larger samples of the women all over the country. It may assist researchers to further investigate and understand 
women dominance and attain generalized findings of more women population. In a comparative study on female within different ethnic and religious group in Iran, it will be beneficial in understanding the prevalence of female dominance on these ethnic groups that constitute an Iranian society. The findings and information acquired from this kind of research may shed enlightenment as to the effects of various factors influencing female dominance, therefore, intervention programs will provide and supply knowledge in the same way.

\section{References}

Hamby, S. L. (1996). The dominance scale. Preliminary psychometric properties. Violence and Victims, 11(3), 199-212.

Krejcie, R. V., \& Morgan, D. W. (1970). Determining sample size for research activities. Educational and Psychological Measurement, 30(607-610).

Lajvardi, H. (1997). power in the family. Tehran university, Tehran

Mahdavi, M. S., \& Saburi, H. (2003). Investigatimg the structure of power distribution in family. Women Studies, 2(1), 29-65.

Mansourian, M. K., \& Ghaderi, F. (2002). Fectors affecting power dominance in families of Shiraz. Scientific Research Journal of the Faculty of Literature and Humanities. Esfahan Universitiy, 2(30 \&31), 269-294.

Ministry of Labour and Social Affairs. (2008). Wage of labour. [Online] Available: www.irimlsa.ir.

Saroukhani, \& Amirpanahi. (2006). Power structure in family and social participation. Journal of Women's Research (PAZHUHISH-I ZANAN), 4(3(15)), 31-60.

Table 1. Background Profile of the Respondents

\begin{tabular}{|c|c|c|c|c|}
\hline Variables & $\mathbf{n}$ & $\%$ & $\mathbf{M}$ & SD \\
\hline Women Age $(n=337)$ & & & 30.77 & 7.96 \\
\hline$<20$ & 20 & 5.93 & & \\
\hline $20-30$ & 179 & 53.12 & & \\
\hline $31-40$ & 97 & 28.78 & & \\
\hline $41-50$ & 34 & 10.09 & & \\
\hline$>50$ & 7 & 2.08 & & \\
\hline Women Years Education $(n=335)$ & & & 9.13 & 3.75 \\
\hline Primary School (1-5) years & 116 & 34.62 & & \\
\hline Secondary School (6-9) years & 57 & 17.01 & & \\
\hline High School (10-13) years & 123 & 36.72 & & \\
\hline University and Above (14 and above) years & 39 & 11.64 & & \\
\hline Duration of Marriage $(n=337)$ & & & 9.62 & 9.09 \\
\hline$<5$ & 156 & 46.29 & & \\
\hline $5-10$ & 83 & 24.63 & & \\
\hline $11-15$ & 24 & 7.12 & & \\
\hline $16-20$ & 24 & 7.12 & & \\
\hline$>20$ & 50 & 14.84 & & \\
\hline & & & & \\
\hline
\end{tabular}




\begin{tabular}{|c|c|c|c|c|}
\hline Number of Children $(n=337)$ & & & & \\
\hline$<2$ & 270 & 80.12 & & \\
\hline $2-4$ & 63 & 18.69 & & \\
\hline $5-7$ & 3 & .89 & & \\
\hline$>7$ & 1 & .29 & & \\
\hline Family Income (Rials) $(n=332)$ & & & 450436 & 352681.83 \\
\hline$<200,000$ & 51 & 15.36 & & \\
\hline $200,000-400,000$ & 151 & 45.48 & & \\
\hline $400,001-600,000$ & 78 & 23.49 & & \\
\hline$>600,000$ & 52 & 15.66 & & \\
\hline
\end{tabular}

Table 2. Correlation Coefficient (r) between Background Profile and Dominance

\begin{tabular}{ll}
\hline \hline \multicolumn{1}{c}{ Backgound Profile } & Dominance \\
\hline & \\
Duration of Marriage & -.037 \\
Women Age & .100 \\
Number of Children & $.151^{* *}$ \\
Family Income & $.245^{* *}$ \\
Women Education & -.103 \\
\hline
\end{tabular}

Table 3. Summary of Regression Analysis of the Main Variables Contributing to Dominance

\begin{tabular}{lccccc}
\hline \hline $\begin{array}{c}\text { Predictors of } \\
\text { DV }\end{array}$ & $\begin{array}{c}\text { Unstandardized } \\
\text { coefficients }\end{array}$ & Std. Error & $\begin{array}{c}\text { Beta } \\
\text { Unstandardized } \\
\text { coefficients }\end{array}$ & $\mathrm{t}$ & p-value \\
\hline constant & 77.336 & 1.089 & & 71.034 & .000 \\
$\begin{array}{l}\text { Number } \\
\text { Children }\end{array}$ & .998 & .452 & .117 & 2.208 & .028 \\
Family Income & 7.077 & .000 & .243 & 4.576 & 00 \\
& & & & & 0 \\
\hline
\end{tabular}

